\title{
The Association between Symptom Accommodation and Emotional Coregulation in Couples with Binge Eating Disorder
}

\author{
DANIELLE M. WEBER* ${ }^{*}$ \\ MELANIE S. FISCHER ${ }^{\star}$ \\ DONALD H. BAUCOM* \\ BRIAN R. W. BAUCOM ${ }^{\dagger}$ \\ JENNIFER S. KIRBY: \\ CRISTIN D. RUNFOLA*, \\ CAMDEN E. MATHERNE \\ CYNTHIA M. BULIK,
}

Intense negative emotions and maladaptive behavioral strategies to reduce emotional distress occur not only in patients with various forms of psychopathology but also in their committed partners. One common strategy to reduce distress is for partners to accommodate to the symptoms of the disorder, which reduces distress short term but maintains symptoms long term. Accommodation is believed to be motivated by the partner reacting behaviorally to the patient's emotions, but the emotions of the partner in this context have yet to be examined. This pilot study examined how partner accommodation related to specific patterns of emotional coregulation between patients with binge eating disorder (BED) and their partners, before and after a couple-based intervention for BED. Vocally encoded emotional arousal was measured during couples' $(\mathrm{n}=11)$ conversations about BED. As predicted, partners' emotional reactivity to patients' emotional arousal was associated with high accommodation before treatment. Thus, partners may use accommodation as a strategy to reduce both the patients' and their own distress. After treatment, partners' arousal was no longer associated with the patients' emotional arousal; instead, partners showed greater emotional stability over time, specifically when accommodation was low. Additionally, patients were less emotionally aroused after treatment. Therefore, treatment may have decreased overall emotionality of patients and altered the association between accommodation and partners' emotional reactivity. If replicated, this understanding of the emotional

\footnotetext{
*Department of Psychology and Neuroscience, University of North Carolina at Chapel Hill, Chapel Hill, NC.

'Department of Psychology, University of Utah, University of Utah, Salt Lake City, UT.

Department of Psychiatry, University of North Carolina at Chapel Hill.

${ }^{\S}$ Department of Psychiatry and Behavioral Sciences, Stanford University, Stanford, CA.

"Department of Nutrition, University of North Carolina at Chapel Hill, Chapel Hill, NC.

"Department of Medical Epidemiology and Biostatistics, Karolinska Institutet, Stockholm, Sweden.

Correspondence concerning this article should be addressed to Danielle M. Weber, University of North Carolina at Chapel Hill, 235 E. Cameron Avenue, Chapel Hill, NC 27599-3270. E-mail: dmweber@ live.unc.edu.

Dr. Runfola was supported by the Global Foundation for Eating Disorders (PIs: Bulik \& Baucom). This investigation was also supported by a grant from the Hilda and Preston Davis Foundation. Dr. Bulik is a consultant and grant recipient from Shire Pharmaceuticals and acknowledges funding from the Swedish Research Council (VR Dnr: 538-2013-8864).

Dr. Runfola conducted this research while at the Department of Psychiatry at the University of North Carolina at Chapel Hill. She is now at the Department of Psychiatry and Behavioral Sciences at Stanford Univeristy.
} 
context associated with accommodation in BED can inform couple-based treatment by targeting specific emotional precipitants of behaviors that maintain symptoms.

Keywords: Emotion Coregulation; Couples; Accommodation; Binge Eating Disorder

Fam Proc 58:920-935, 2019

$\mathrm{E}$ motion regulation is understood as a set of intra- and interpersonal processes that influence the occurrence, duration, and intensity of emotions (e.g., Butler \& Randall, 2013). The ability to regulate emotions effectively is critical to psychological and physical well-being (e.g., Eisenberg, Fabes, Guthrie, \& Reiser, 2000; John \& Gross, 2004). Furthermore, deficits in emotion regulation, such as the frequent experience of intense negative emotions and the reliance on maladaptive behavioral strategies to reduce negative emotions (e.g., binge eating, substance use, and self-injurious behaviors), are linked to various forms of psychopathology (Werner \& Gross, 2010). Given the multifaceted nature of emotion regulation and the deleterious consequences of deficits in this area, extensive research has explored emotion regulation at the individual level. However, emotions typically do not occur within a vacuum; the presence of close others can influence emotions and their regulation (e.g., Butler, 2011; Sbarra \& Hazan, 2008). Ideally, close others facilitate regulation by promoting emotional stability while reducing the burden on the individual to regulate individually (Coan \& Maresh, 2014). Under less ideal circumstances, close others can inhibit effective regulation (Sbarra \& Hazan, 2008), such as prolonging the duration or increasing the intensity of negative emotions. Given that the majority of adults are in committed romantic relationships (U.S. Census Bureau, 2016), examining emotion regulation within a couple context is critical to provide insight into the process of emotion regulation for both individuals.

Most research on interpersonal emotion regulation has focused on healthy couples. In this context, calling on a partner to assist in emotion regulation may be an adaptive way to regulate an acutely negative experience (e.g., Butler \& Randall, 2013). However, interpersonal processes to regulate emotions appear to be more complex for individuals with psychopathology. These individuals often have difficulties regulating emotions (Werner \& Gross, 2010), and they experience interpersonal difficulties (e.g., Baucom, Belus, Adelman, Fischer, \& Paprocki, 2014) which may make it difficult to work together as a couple to regulate emotions adaptively. When a partner witnesses the patient in distress, that is, experiencing and expressing intense negative emotions, the partner often searches for ways to help (e.g., Fredman, Vorstenbosch, Wagner, Macdonald, \& Monson, 2014). Not knowing how to respond adaptively, partners may engage in strategies that alleviate distress in the short term but are not helpful for the patient long term (Fischer, Baucom, \& Cohen, 2016).

One way that partners respond to patients' negative emotions is to engage in behaviors that help the patient immediately avoid or escape intense emotional experiences. Whereas behaviors such as providing reassurance in response to anxiety or completing tasks that the individual would rather avoid could be considered social support under adaptive circumstances, if they serve to maintain the disorder, these partner behaviors are known as symptom accommodation. ${ }^{1}$ Despite the reduction or prevention of patients' distress in the short term, accommodation can reinforce maladaptive behaviors and emotion regulation strategies in the long term (Salkovskis, 1996). Accommodation takes different forms depending on the disorder, such as the partner participating in compulsive rituals (e.g.,

\footnotetext{
${ }^{1}$ This understanding of accommodation should not be confused with Rusbult, Verette, Whitney, Slovik, and Lipkus's (1991) conceptualization of "accommodation" as a willingness to engage in constructive rather than maladaptive behaviors in relationships.
} 
checking multiple times that the stove is turned off) in obsessive-compulsive disorder (OCD; Boeding et al., 2013) or restricting food availability in eating disorders (Treasure \& Todd, 2016). For example, by keeping most foods out of the house, the partner may help the patient avoid immediate distress regarding being triggered to binge eat, but this strategy also prevents the patient from learning how to cope adaptively with the presence of food, which would be important for long-term recovery. Therefore, engaging in accommodation may help in the short term but be problematic for maintenance of the disorder in the long term. Across disorders, accommodation has been associated with more severe symptoms (Boeding et al., 2013; Caporino et al., 2012; Salerno et al., 2016), worsened treatment response (Boeding et al., 2013; Salerno et al., 2016), and lower relationship satisfaction (Boeding et al., 2013; Fredman et al., 2014). Thus, accommodation is an important interpersonal treatment target, and understanding what contributes to accommodation behaviors has the potential to help optimize interventions.

Past research has explored how caregiver characteristics such as anxiety and depression (Caporino et al., 2012; Sepulveda, Kyriacou, \& Treasure, 2009) and empathy toward the ill individual (Caporino et al., 2012; Reuman \& Abramowitz, 2017) are related to accommodation. Although this research has attempted to identify characteristics associated with more accommodation in a caregiver, this research does not clarify how momentary reactions to the distress of the patient relate to accommodation. Importantly, partners' behaviors can be motivated not only by the patients' emotions but also their own. It is reasonable to expect partners to become emotionally aroused themselves upon witnessing the patients' emotional arousal and then accommodate to alleviate both their own and their partner's negative emotions (Boeding et al., 2013; Fischer et al., 2017). For example, Fischer et al. (2017) found that partners were highly reactive to OCD patients' distress (i.e., partners become more emotionally aroused in response to patients' arousal) and proposed that the emotional reactivity of the partner may motivate accommodation. However, in Fischer et al.'s investigation, accommodation was not directly assessed. Examining how partners' emotions relate to accommodation would be an important extension of past research and provide insight into factors that contribute to partners' maladaptive responses to patients' emotional arousal across various forms of psychopathology.

The findings from Fischer et al. (2017) can be understood within the context of "coregulation." Coregulation refers to the bidirectional linkage of emotions between partners, providing more efficient stability for both individuals (Butler \& Randall, 2013). In the context of a couple's conversation, coregulation may be present when the ups and downs of one partner's emotions are linked to the emotions of the other partner, such as when one partner escalates in emotion arousal and the other partner responds by becoming more emotionally aroused. Research has suggested that the emotional linkage that is part of coregulation may be either maladaptive or adaptive, depending on the context (Fischer et al., 2017; Randall, Post, Reed, \& Butler, 2013; Timmons, Margolin, \& Saxbe, 2015). In healthy couples, one partner expressing distress and the other partner showing similar distress could signal empathy and promote bonding. However, individuals with psychopathology are frequently emotionally distressed. If the partner is highly reactive to that distress, partners may be motivated to alleviate that distress in the moment-even if those behaviors reinforce symptoms long term. Therefore, as proposed by Fischer et al. (2017), in the context of psychopathology, coregulation of emotion could be associated with maladaptive strategies such as accommodation.

Examining emotional coregulation requires a time-sensitive methodology. Vocal indicators of emotion are a prime method for assessing emotional arousal on a fine-grained basis during interpersonal interactions, given that vocal indicators are sensitive to subtle changes and are inherently communicative (Baucom, 2010). That is, humans can detect subtle vocal changes that signal distress in an individual (e.g., Juslin \& Scherer, 2005) 
and reflect both physical and emotional pain (e.g., social rejection) (Eisenberger \& Lieberman, 2004). One vocal feature that has established validity as a strong indicator of emotional arousal (or "activation" in the voice; see Scherer, 1986) is fundamental frequency $\left(f_{0}\right.$; see Bachorowski \& Owren, 1995, and Juslin \& Scherer, 2005 for a review). Fundamental frequency has increasingly been explored within dyadic contexts (e.g., for a review see Weusthoff, Baucom, \& Hahlweg, 2013), both as an indicator of overall emotional arousal in couples (Baucom et al., 2011; Baucom, Weusthoff, Atkins, \& Hahlweg, 2012; Fischer et al., 2015) as well as an indicator of the coregulation of emotional arousal between partners across the course of a conversation (Baucom et al., 2015; Baucom, Sheng et al., 2015; Fischer et al., 2017). $F_{0}$ has been associated with a variety of relationship outcomes among couples without psychopathology (Baucom et al., 2011, 2015, 2012; Fischer et al., 2015), and recently, $f_{0}$ methodology has been extended to explore coregulation in couples with psychopathology (Fischer et al., 2017) and individuals in client-therapist interactions (Bryan et al., 2018). Thus, this methodology offers a temporally sensitive and empirically valid way of measuring emotions between and within patient and partner across time.

The current pilot investigation explored the role of accommodation and coregulation in the context of binge eating disorder (BED), a disorder marked by difficulty with emotion regulation (e.g., Leehr et al., 2015). BED is characterized by recurrent episodes of binge eating (eating objectively large amounts of food in a given period and feeling a loss of control over eating) that are associated with distress (American Psychiatric Association, 2013). Binge eating in BED is believed to function as a strategy to reduce negative emotions (Heatherton \& Baumeister, 1991). Although research has supported that binge episodes are often triggered by negative emotions, research is mixed regarding the effectiveness of binge eating in reducing negative emotions (Leehr et al., 2015). Given the limits of this strategy, patients with BED may call on a partner to help reduce their distress. In turn, partners may experience their own distress and respond in ways to reduce the negative emotions, such as by accommodating to the patient's symptoms.

This study is a pilot examination of the temporal patterns of association between the emotional arousal of patients with BED and their partners, and how this linkage is related to the partners' accommodation in a small sample of couples who completed a couple-based treatment for BED (Kirby, Runfola, Fischer, Baucom, \& Bulik, 2017). Given that accommodating behaviors are believed to reinforce symptoms in the long term and that accommodation has been empirically related to more severe symptoms and worsened treatment response across disorders, we expected that greater accommodation would be related to higher symptom severity both pre- and posttreatment. Thus, we anticipated that partners who are highly accommodating will be partnered to patients who have more severe symptoms at pretreatment and posttreatment. We hypothesized that in the context of higher emotional arousal overall, partners may be more accommodating; therefore, we expected to see an association between accommodation and overall emotional arousal. In addition, we also expected within-conversation patterns of emotional arousal to predict accommodation. We hypothesized that an increase in the patient's emotional arousal would be associated with an increase in the partner's arousal, and this pattern would be stronger among partners who engage in more accommodation. That is, partners who are emotionally reactive to the patients' emotions may be especially likely to use accommodation as a strategy to alleviate emotional arousal, as accommodation could decrease the arousal of both patient and partner. The couples in this investigation participated in an open trial of a couple-based intervention for BED, which targeted improving communication around the disorder, behavioral change skills, and improving emotion regulation. Thus, the interpersonal, behavioral, and emotional focus of this treatment should translate to changes in how this coregulation between patient and partner arousal relates to accommodation. Specifically, we hypothesized that the overall level of emotional arousal of patient and 
partner during conversation would decrease after treatment, as a function of the couple learning to communicate about the disorder with less emotional intensity. Additionally, because partners should learn more adaptive ways to respond to emotions in treatment, we hypothesized that emotion coregulation would no longer be related to accommodation posttreatment. Given the small sample included in this investigation, all findings must be interpreted cautiously, even when results are consistent with the hypotheses.

\section{METHOD}

\section{Participants}

Participants included 11 adult opposite-sex couples who took part in a couple-based intervention for BED (UNITE; described below). There were more female $(n=8)$ than male $(n=3)$ patients, and there were more male $(n=8)$ than female $(n=3)$ partners. Patients' average age was $48.45(S D=12.03)$, and partners' average age was $51.18(S D=14.40)$. Ninety-one percent of participants were White. All participants had at least some college or technical education, with the majority of participants holding either a college degree $(45.5 \%)$ or a postgraduate degree $(45.5 \%)$. Individual yearly income ranged from below $\$ 5,000(13.6 \%)$ to over $\$ 100,000$ (13.6\%), with the median income being between $\$ 50,000$ and 74,999. Half of the individuals in the sample $(n=11)$ had children, either from their current or a past relationship. Couples had been romantically involved for an average of 16.19 years $(S D=13.84)$. Individuals were recruited for UNITE if they met DSM-5 criteria for BED or otherwise-specified feeding or eating disorder (OSFED) binge eating type, were in a committed, cohabitating relationship for at least 6 months, and the partner was willing to participate. Additionally, participants needed to be at least 18 years old, English-speaking, participate in individual outpatient treatment and medical monitoring, and have health insurance. Exclusion criteria included alcohol or drug dependence in the past year; current significant suicidal ideation; severe depression; developmental disability that would impair treatment participation; any psychosis, schizophrenia, or bipolar I disorder unless stably remitted for $\geq 1$ year; moderate-to-high levels of physical violence from either partner; previous participation in related studies conducted by study staff; and having postbariatric surgery. Patients and partner diagnoses were assessed via the Structured Clinical Interview for DSM-IV Patient Edition (First, Spitzer, Gibbon, \& Williams, 1996) and NonPatient Edition (First, Spitzer, Gibbon, \& Williams, 1997) with an expanded module for eating disorder diagnosis updated for DSM-5. Comorbid diagnoses included major depressive disorder (current 18.2\%, lifetime 72.7\%), dysthymia (current 0\%, lifetime 9.1\%), alcohol abuse disorder (current $0 \%$, lifetime 36.4\%), generalized anxiety disorder (current $27.3 \%$, lifetime 27.3\%), panic disorder (current 0\%, 19.2\% lifetime), social phobia (current 27.3\%, lifetime $27.3 \%$ ), specific phobia (current $18.2 \%$, lifetime $18.2 \%$ ), and posttraumatic stress disorder (current $9.1 \%$, lifetime $9.1 \%$ ). In the one couple in which both individuals met criteria for $\mathrm{BED}$, the individual with more severe $\mathrm{BED}$ symptoms at baseline was considered the "patient" and the one with less severe symptoms was considered the "partner" for the purposes of this study. One couple dropped out after session 12 (of 22 total sessions), but all other couples $(n=10)$ completed assessments at pre- and posttreatment.

\section{Materials}

\section{Emotional arousal}

Emotional arousal was measured with vocal fundamental frequency $\left(f_{0}\right)$ gathered from recordings of couple interactions. $F_{0}$ is a feature of speech prosody closely associated with perceived pitch (Atkinson, 1978) that represents the lowest-frequency harmonic of the 
speech sound wave, with higher values of $f_{0}$ indicating more rapid opening and closing of vocal folds during speech production (Juslin \& Scherer, 2005). $F_{0}$ is best understood as a broad measure of emotional arousal, given that $f_{0}$ has been associated with higher arousal across various emotions, rather than being specific to any given emotion (see Baucom, 2010, for a discussion; Banse \& Scherer, 1996; Juslin \& Scherer, 2005). In this study, $f_{0}$ mean was used as the index of emotional arousal, given its strong empirical support as a measure of emotional arousal while also being less sensitive to extreme values that disadvantage the use of $f_{0}$ range (e.g., Baucom, 2010; Baucom et al., 2011). $F_{0}$ estimates (in hertz, or $\mathrm{Hz}$ ) for every 0.25 second were obtained with Praat (Boersma \& Weenink, 2018) with a bandpass filter of $75-300 \mathrm{~Hz}$ to restrict extracted values to the range of adult speech (Owren \& Bachorowski, 2007). $F_{0}$ was calculated in two ways: (a) for each talk turn for analyses involving coregulation and (b) aggregated across the entire conversation. The number of talk turns varied across couples; at pretreatment, the average number of talk turns was $48.18(S D=19.25)$ and at posttreatment was $37.40(S D=22.17)$. Overall $f_{0}$ mean for patients at pretreatment was $159.66(S D=26.69)$ and at posttreatment was $139.83(S D=22.88)$, whereas partners' $f_{0}$ mean at pretreatment was $127.93(S D=26.41)$ and at posttreatment was $121.39(S D=24.40)$. Mean differences between patients and partners are partially due to a higher proportion of females among patients.

\section{Symptom severity}

Patients completed the Binge Eating Scale (BES; Gormally, Black, Daston, \& Rardin, 1982), a 16-item self-report questionnaire assessing binge eating behaviors and cognitions. Sample items for the BES include "I usually am able to stop eating when I want to. I know when "enough is enough" (indicating a low value) to "I feel incapable of controlling urges to eat. I have a fear of not being able to stop eating voluntarily." The BES has good internal consistency (Gormally et al., 1982) and test-retest reliability ( $r=.87$; Timmerman, 1999). The BES has been found to validly discriminate across levels of binge eating severity (Gormally et al., 1982; Timmerman, 1999). In the current sample, the BES had a high internal consistency (pretreatment $\alpha=.91$, posttreatment $\alpha=.90$ ). The average BES score at pre- was $28.55(S D=8.61)$ and at posttreatment was $13.10(S D=8.65)$.

\section{Accommodation}

Partners completed the Accommodation and Enabling Scale for Eating Disorders (AESED; Sepulveda et al., 2009), a 33-item self-report questionnaire which assesses caregivers' behaviors (language modified to be specific to partners) which reinforce eating disorder symptoms. Several items capture the extent to which a partner may generally help the patient avoid what makes them anxious (as might be seen across psychopathology), whereas other items are much more focal to the eating disorder, such as addressing accommodation of maladaptive meal routines. Sample items for the AESED included "Does your partner engage you in repeated conversations about whether it is safe or acceptable to eat certain foods?" and "Does your partner with an eating disorder control the choices of food that you buy?" The AESED has good internal consistency $(\alpha=.92)$ and convergent and discriminant validity (Sepulveda et al., 2009). In the current sample, the AESED had high internal consistency (pre- and posttreatment $\alpha=.87$ ). The average AESED score at pretreatment was $30.09(S D=14.92)$ and at posttreatment was 29.92 $(S D=14.50)$. A higher score indicates more partner accommodating behaviors.

\section{Procedure}

All procedures were approved by the University of North Carolina at Chapel Hill's Institutional Review Board. Data consisted of a subset of measures from an open trial of a 
couple-based intervention for BED (Runfola et al., in press). As part of the treatment protocol, couples participated in 9- to 10-minute recorded interactions before and after treatment. For one interaction, an error resulted in the recording ending at 6:43 minutes, but all other recordings lasted between 9 and 10 minutes. A research assistant helped the couple select a topic of BED-related concern of medium intensity about which the couple would share their thoughts and feelings. The research assistant left the room once the topic was selected and returned at the end of the interaction. The audio recordings were later processed with Audacity 2.2.2 (Audacity Team, 2018) and Praat (Boersma \& Weenink, 2018) to separate speaker tracks and generate $f_{0}$ values.

\section{Treatment}

UNITE (Uniting Couples in the Treatment of Eating Disorders; Kirby, Runfola, Baucom, \& Bulik, 2014) for BED is a manualized 22-session structured couple-based intervention that employs a cognitive behavioral couple therapy approach integrated with strategies from individual cognitive behavioral therapy for BED. UNITE targets include improved communication around BED, interpersonal problem-solving and behavioral change skills, and partner-assisted emotion regulation. Thus, this treatment directly targets how to foster more effective communication around symptoms and aims to reduce patterns which maintain the disorder, while also building emotion regulation strategies.

\section{RESULTS}

\section{Data Analytic Plan}

Analyses at the couple level (one observation per couple, such as symptom severity and accommodation) were conducted using linear regression models in SPSS 24 (IBM Corp, 2016). All other analyses were conducted in SAS 9.4 (SAS Institute Inc, 2013) using a multilevel modeling (MLM) approach with PROC MIXED to account for nonindependence in data caused by nesting of individuals within couples and talk turns within individuals. Due to the small group-level sample size which can result in biased estimates in MLM (Maas \& Hox, 2005), a Kenward-Roger correction for small samples was used, which mitigates potential bias (Kenward \& Roger, 2009) and outperforms other modeling approaches for small, nested samples such as generalized estimating equations (GEEs; McNeish \& Stapleton, 2016). All MLMs were conducted as two-intercept models for distinguishable dyads, which are a variation of multivariate MLMs (Kenny, Kashy, \& Cook, 2006) and result in separate estimates for patients and partners while accounting for nesting in the data. Cross-lagged actor-partner interdependence models (APIMs; Kenny et al., 2006) tested coregulation of emotional arousal across the conversation as indicated by the crosspartner effects. Random intercepts for patient and partner separately were estimated for all models. For all models with accommodation, the total score of accommodation was grand mean centered prior to analysis. Given the imbalance of gender within the patients and partners, gender was included as a covariate.

Diagnostics were conducted based on a cross-lagged APIM without additional predictors to examine outliers with undue influence on the model. For each couple, a model-level test of influence (DFFITs) was conducted in R studio (R Studio Team, 2015). Based on these diagnostics, a small number $\left(1.9 \%\right.$ at pretreatment and $2.9 \%$ at posttreatment) of $f_{0}$ observations at the talk turn level was identified to have undue influence on the model results. We conducted sensitivity analyses and found greater stability of model estimates with observations removed. Therefore, final analyses were conducted with these talk turns removed. 


\section{Hypothesis Testing}

\section{Accommodation and symptom severity}

To test the hypothesis that higher pretreatment accommodation in partners is related to higher concurrent symptom severity in patients at pretreatment, a linear regression was conducted with accommodation and gender predicting binge eating severity. The overall model was not significant, $F(2,8)=2.04, p=.193$. The association between accommodation and binge eating severity was not significant, $B=-0.10, t=-0.50, p=.632$. The effect of gender also was not significant, $B=11.98, t=1.93, p=.090$. These results fail to support the hypothesis that patients with more severe symptoms are paired with partners who are more accommodating. To explore whether greater pretreatment accommodation in partners was related to worse treatment outcome, a linear regression was conducted predicting posttreatment binge eating severity from accommodation, controlling for pretreatment severity and gender. The overall model was not significant, $F(3,6)=1.75$, $p=.256$. When controlling for both pretreatment severity and gender, accommodation was not significantly related to posttreatment severity, $B=0.34, t=1.58, p=.165$. However, accommodation explained $17 \%$ of the variance in posttreatment severity beyond the effects of pretreatment severity and gender (adjusted $R^{2}$ change).

\section{Accommodation and aggregate emotional arousal}

To examine associations of conversation-level arousal with accommodation, two-intercept MLMs were tested with interaction terms between each intercept and accommodation predicting aggregate arousal. Due to the small sample size, two separate models were tested for pre- and posttreatment. Before treatment, aggregate $f_{0}$ mean for neither patients $(B=-0.62, S E=0.42, p=.181)$ nor partners $(B=-0.46, S E=0.35, p=.228)$ was associated with accommodation. After treatment, effects similarly failed to emerge for both patients $(B=-0.28, S E=0.37, p=.472)$ and for partners $(B=0.58, S E=0.43$, $p=.219$ ). This suggests that global levels of accommodation did not predict the average level of emotional arousal of the patients and partners for the conversation as a whole.

\section{Accommodation and coregulation of emotional arousal}

Two-intercept, cross-lagged actor-partner interdependence models (APIMs; Kenny et al., 2006) were used to test cross-partner effects of emotional arousal across the conversation (see Figure 1). For both the patient and partner, their $f_{0}$ mean at a given talk turn $i$ is predicted by their own $f_{0}$ mean at their previous talk turn $i-1$ ("actor effects" for patients and partners, see paths $1 \mathrm{a}$ and $2 \mathrm{a}$ in Figure 1) and the other person's $f_{0}$ mean at their immediately preceding talk turn ("partner effects," see paths $1 \mathrm{~b}$ and $2 \mathrm{~b}$ in Figure 1). Accommodation was added as a level-2 predictor, and the cross-level interaction between accommodation and the partner effect for partners (path $2 b$ ) was the focus of analyses. Given the small sample and model complexity, separate APIMs were estimated for preand posttreatment, which are described by the following series of equations:

Level-1: $f_{0} \operatorname{mean}_{i j}=$ Patient $*\left[\beta_{1 j}(\right.$ intercept $\left.)+\beta_{3 j}\left(\operatorname{actor}_{f_{0} \operatorname{mean}_{(i-1) j}}\right)+\beta_{5 j}\left(\operatorname{partner}_{f_{0} \operatorname{mean}_{(i-1) j}}\right)\right]$

$$
+\operatorname{Partner} *\left[\begin{array}{r}
\beta_{2 j}(\text { intercept })+ \\
+\beta_{4 j}\left(\operatorname{actor}_{\left.f_{0} \operatorname{mean}_{(i-1) j}\right)}\right) \\
+\beta_{6 j}\left(\operatorname{partner}_{f_{0} \operatorname{mean}_{(i-1) j}}\right)
\end{array}\right]+r_{i j}
$$

Level- 2 : for $i=1$ to $6, \beta_{i j}=\gamma_{i 0}($ intercept $)+\gamma_{i 1}($ accommodation $)$ 


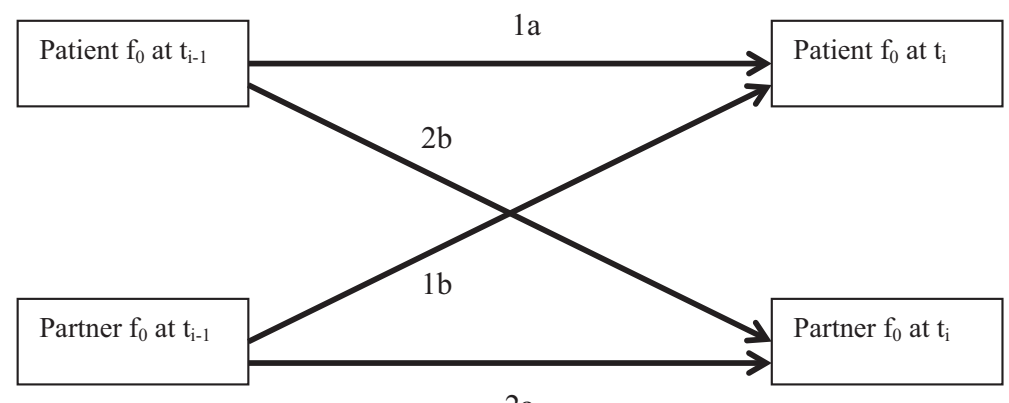

$2 \mathrm{a}$

FIGURE 1. Conceptual Diagram of Cross-Lagged APIM (Actor-Partner Interdependence Model).

Note. 1 indicates predictors influencing the $f_{0}$ of the patient at a particular point in time, whereas 2 indicates predictors influencing the $f_{0}$ of the partner at a particular point in time. Path a represents the actor effects, while path b represents the (cross-)partner (i.e., coregulation) effects. Thus, $2 \mathrm{~b}$ represents how the patient's $f_{0}$ at the previous time point predicts the partner's $f_{0}$ at the subsequent time point.

where $i$ indexes talk turns and $j$ indexes couples. Level-2 random effects were included on $\beta_{1 j}$ and $\beta_{2 j}$. All $f_{0}$ predictors were person-mean centered. Significant interactions between cross-partner effects and accommodation were probed by generating simple slope estimates at different levels (mean $\pm 1 S D$ ) of accommodation.

Results of the cross-lagged APIM examining differences in coregulation as a function of accommodation at pretreatment are presented in Table 1. As hypothesized, a significant cross-level interaction emerged between the cross-partner effect (path 2b) and accommodation. Probing of this interaction revealed that specifically at high (mean $+1 S D$ ) levels of accommodation, there was a significant and positive cross-partner effect for the partner. That is, in the context of high partner accommodation, patients' emotional arousal at any given time predicted the partners' subsequent arousal at the next time point. In other words, if patients' emotional arousal was unusually high relative to their average level, partners who showed high levels of accommodation were reactive and their emotional arousal increased as well. This cross-partner effect for the partner was not significant at average or low levels of accommodation. Of note, there was no actor effect for either patients or partners. Taken together, only the partners' arousal was predictable (based on the patients' previous arousal), whereas the patients' emotional arousal was not associated with either their own or the partners' previous arousal.

Results of the cross-lagged APIM examining differences in coregulation as a function of accommodation at posttreatment are presented in Table 2. As anticipated, the interaction between the cross-partner effect (path $2 \mathrm{~b}$ ) and accommodation was no longer significant. To test whether the magnitude of these effects were significantly different at pre- and posttreatment, we followed recommended procedures (Kleinbaum \& Kupper, 1978) for calculating a $z$ score of the difference in these two effects. This effect, $z=1.58$, was nonsignificant at a one tailed (given our assumption that the effect at posttreatment would be smaller than the effect at pretreatment), $z_{\text {critical }}$ value of 1.65 . Therefore, the size of the change in effect from pre- to posttreatment was not sufficient to be a significant difference. However, the fact that the interaction between partners' emotional reactivity and accommodation at posttreatment is not significant nevertheless suggests that the pattern we observed at pretreatment is not prominent among couples at posttreatment. The posttreatment model revealed a significant cross-level interaction between the partners' actor effect (path 2a) and accommodation. Probing of this interaction revealed that at low levels of accommodation, there 
TABLE 1

Fixed Effects for the Cross-Lagged APIM at Pretreatment: Differences in Actor/Partner Effects by Partner Accommodation (AESED)

\begin{tabular}{lcccc}
\hline Effect & Estimate $(\boldsymbol{S E})$ & $\boldsymbol{D F}$ & $\boldsymbol{t}$ & $\boldsymbol{p}$ \\
\hline Patients & & & & \\
Intercept & $147.38(5.11)$ & 8.78 & $28.86^{* * *}$ & $<.0001$ \\
Intercept*Gender & $63.99(10.94)$ & 8.63 & $5.85^{* * *}$ & .0003 \\
Actor effect & $-0.07(0.06)$ & 245 & -1.11 & .266 \\
Partner effect & $0.10(0.08)$ & 246 & 1.24 & .218 \\
Intercept*AESED & $-0.66(0.34)$ & 7.87 & -1.98 & .084 \\
Actor effect*AESED & $-0.003(0.004)$ & 245 & -0.65 & .514 \\
Partner effect*AESED & $-0.001(0.006)$ & 245 & -0.18 & .854 \\
Partners & & & & \\
Intercept & $138.95(5.09)$ & 8.16 & $27.29^{* * *}$ & $<.0001$ \\
Intercept*Gender & $43.36(10.92)$ & 8.05 & $3.97^{* *}$ & .004 \\
Actor effect & $0.12(0.06)$ & 245 & 1.83 & .068 \\
Partner effect & $0.09(0.05)$ & 245 & 1.78 & .076 \\
Intercept*AESED & $-0.53(0.34)$ & 7.53 & -1.57 & .157 \\
Actor effect*AESED & $0.002(0.004)$ & 245 & 0.55 & .580 \\
Partner effect*AESED & $0.007(0.003)$ & 245 & $1.97^{*}$ & .0498 \\
$\quad$ Simple slope at low AESED (-1 SD) & $-0.006(0.07)$ & 245 & -0.08 & .935 \\
$\quad$ Simple slope at average AESED & $0.09(0.05)$ & 245 & 1.78 & .076 \\
$\quad$ Simple slope at high AESED (+1 SD) & $0.19(0.07)$ & 245 & $2.70^{* *}$ & .008 \\
\hline
\end{tabular}

Notes. AESED = Accommodation and Enabling Scale for Eating Disorders; APIM = Actor-Partner Interdependence Model.

$* * * p<.001, * * p<.01,{ }^{*} p<.05$.

was a positive actor effect for the partner. Because this actor effect is closer to a value of 1.0, it indicates that partners' arousal is more stable over time when accommodation was lower relative to when accommodation was higher (Perry et al., 2017).

\section{Change in $f_{0}$ across treatment}

A two-intercept MLM was employed to test changes in aggregate-level emotional arousal from pre- to posttreatment, including the two intercepts and a dummy-coded variable to indicate treatment time point, with pretreatment serving as the reference group, and controlling for gender. As hypothesized, there was a significant reduction in aggregate $f_{0}$ mean for patients, which dropped by $17.60 \mathrm{~Hz}(S E=5.38)$ from before to after treatment, $t(16.40)=-3.27, p=.005$. Thus, patients' overall levels of emotional arousal decreased as a function of treatment. While aggregate $f_{0}$ mean dropped for partners by $7.25 \mathrm{~Hz}$ $(S E=5.38)$, this difference failed to reach significance, $t(16.30)=-1.35, p=.196$.

\section{Summary}

Pretreatment accommodation was neither significantly related to the patients' pre- or posttreatment symptom severity. Average levels of arousal did not relate to accommodation, but noteworthy patterns emerged for coregulation of arousal within the conversation. Specifically, the partners' emotional arousal was reactive to the patients' arousal, in that higher patient arousal was associated with higher subsequent arousal in the partner-but only among partners who were highly accommodating. This occurred in the context of the patients' arousal being unpredictable by either their own or the partners' previous arousal. Importantly, this effect was not significant after treatment, and for couples with low levels of accommodation, partners' emotional arousal became more stable. Across 
TABLE 2

Fixed Effects for the Cross-Lagged APIM at Posttreatment: Differences in Actor/Partner Effects by Partner Accommodation (AESED)

\begin{tabular}{lcccc}
\hline Effect & Estimate $(\boldsymbol{S E})$ & $\boldsymbol{D F}$ & $\boldsymbol{t}$ & $\boldsymbol{p}$ \\
\hline Patients & & & & \\
Intercept & $133.79(6.14)$ & 6.84 & $21.78^{* * *}$ & $<.0001$ \\
Intercept*Gender & $39.56(12.30)$ & 6.83 & $3.22^{*}$ & .015 \\
Actor effect & $0.04(0.08)$ & 166 & 0.57 & .570 \\
Partner effect & $-0.27(0.14)$ & 168 & -1.85 & .066 \\
Intercept*AESED & $-0.28(0.41)$ & 6.58 & -0.70 & .510 \\
Actor effect*AESED & $0.008(0.005)$ & 166 & 1.49 & .137 \\
Partner effect*AESED & $-0.007(0.008)$ & 168 & -0.85 & .397 \\
Partners & & & & \\
Intercept & $130.53(7.16)$ & 6.94 & $18.24^{* * *}$ & $<.0001$ \\
Intercept*Gender & $38.30(14.34)$ & 6.94 & $2.67^{*}$ & .032 \\
Actor effect & $0.04(0.08)$ & 169 & 0.43 & .667 \\
Partner effect & $-0.05(0.05)$ & 169 & -1.03 & .301 \\
Intercept*AESED & $0.58(0.48)$ & 6.89 & 1.22 & .263 \\
Actor effect*AESED & $-0.01(0.005)$ & 169 & $-2.41^{*}$ & .017 \\
$\quad$ Simple slope at low AESED (-1 SD) & $0.21(0.09)$ & 169 & $2.25^{*}$ & .026 \\
$\quad$ Simple slope at average AESED & $0.04(0.08)$ & 169 & 0.43 & .667 \\
$\quad$ Simple slope at high AESED (+1 SD) & $-0.14(0.12)$ & 170 & -1.12 & .266 \\
Partner effect*AESED & $0.0007(0.003)$ & 169 & 0.22 & .823 \\
\hline
\end{tabular}

Notes. AESED = Accommodation and Enabling Scale for Eating Disorders; APIM = Actor-Partner Interdependence Model.

$* * * p<.001, * * p<.01,{ }^{*} p<.05$.

treatment, patients' overall emotional arousal decreased; no other effects predicting the patients' arousal emerged.

\section{DISCUSSION}

This pilot study examined emotional coregulation of BED patients and their partners in the context of partners' accommodation of symptoms. Importantly, the findings indicate that before treatment, partners were reactive to the emotional arousal of the patients, in that their emotional arousal increased following an increase in the arousal of the patients; however, this pattern only existed for partners who reported high levels of accommodation. This finding suggests that partners might be accommodating as a response to their own emotional reactivity to the patients' emotional expression within conversations. Thus, when partners become emotionally aroused following patients' increased emotional arousal, this context of high emotional reactivity might activate the partner toward an accommodation strategy to escape these aversive emotions. Accommodation has been proposed as a strategy for partners to manage their own distress (Boeding et al., 2013; Fischer et al., 2017), but this link had not been shown empirically prior to the current findings.

Surprisingly, accommodation was not related to symptom severity. Given that accommodation previously has been linked to symptom severity in anorexia nervosa (Salerno et al., 2016) and to symptom severity in OCD (Boeding et al., 2013; Caporino et al., 2012), it remains unclear why this study did not replicate this effect. Importantly, the size of our sample restricted the power for these couple-level (as opposed to the within-conversation) analyses. Future research is needed to further evaluate the association between accommodation and symptom severity. Accommodation also was not found to be related to the overall arousal level of the patient or partner, either before or after treatment. Therefore, it 
may be that how emotionally arousing a conversation is overall does not predict accommodation; rather, the findings suggest that it is the nuanced pattern of arousal that develops across talk turns that predicts accommodation. More specifically, it is the degree to which partners react to the emotional arousal of patients in the moment that predicts more accommodation. The lack of findings at the overall conversation level but the intriguing patterns at the talk turn level further necessitate the need for research to examine couples' emotional patterns at a fine-grained level.

The results suggest that treatment operated in two major ways relative to arousal. First, although the lack of a control group prevents us from determining that this effect is unique to UNITE-BED, there was a decrease in the overall arousal of the patient from pre- to posttreatment. Given the specific targets of treatment, this overall reduction in emotional arousal could be an indicator of positive treatment response. Along with directly targeting emotion regulation skills, treatment also may have indirectly influenced the emotions of the patient by targeting more balanced and less emotionally driven responses to eating as well as promoting more effective communication of emotions with the partner. Thus, this decrease in emotional arousal following treatment may indicate that patients are able to communicate with their partners without becoming as emotionally aroused, and this dampened emotional arousal may even persist in situations outside of direct interactions with the partner, such as when relating to food in general. Treatment outcome is outside of the scope of this investigation, but these findings are consistent with the general high level of effectiveness of this treatment in this sample (Runfola et al., in press).

Second, the pattern of coregulation of emotional arousal between patient and partner emerged differently in models for pre- and posttreatment. While the change in the magnitude of the effect from pre- to posttreatment was not statistically significant, the partners' reactivity to patients' arousal at high levels of accommodation that was present prior to treatment was nevertheless no longer significant after treatment. Although we could not determine that treatment alone caused this change, these findings are consistent with an interpretation that the treatment altered the emotional context in which accommodation occurs. Given that partners received training in emotion regulation skills and how to manage the symptoms of the patient, the posttreatment results could indicate that partners learned more adaptive ways of responding to the patient's emotional arousal. Rather than being reactive to the emotions of the patient, partners' arousal was increasingly stable at lower levels of accommodation. This predictability of arousal across talk turns within the partner is generally considered normative as individuals' own arousal tends to fluctuate around an individual-level baseline. However, research examining couples with psychopathology found within one sample (OCD) that this individual predictability was also absent (Fischer et al., 2017), suggesting that the presence of some types of psychopathology - with its characteristic higher degree of negative and sometimes labile emotionsmay offset the stability that is expected within individuals. This appears to extend to partners who do not have the disorder. Given that the partners were no longer reactive to the emotions of the patient posttreatment, the resultant environment may be more stable such that partners' emotions are more predictable. Importantly, this finding emerged only when accommodation was low. The specific reason for this effect is hard to elucidate; however, following our previous logic, it may be that accommodation is a behavioral strategy engaged in by partners as a response to the emotional environment. When partners' own emotions feel more stable, partners may be less compelled to accommodate. The reverse causality could also be true: If a partner does not accommodate, this might create an environment that allows stability in the partner's emotions. Future research could explore these nuanced linkages between stability of emotions and precipitants of accommodation. 
In considering the findings, the limitations of this study must be taken into account. First, given that this is a pilot study, the size of the sample restricted the power to detect small effects. Second, all couples took part in a couple-based intervention for BED, and therefore we cannot generalize the pretreatment findings to non-treatment-seeking couples, or to couples in which patients sought individual treatment. In addition, the lack of a control group limits our ability to infer that observed changes were due to the effect of the intervention. Moreover, because couples completed assessments at pre- and posttreatment rather than periodically throughout the treatment, we cannot sensitively detect patterns of change during the treatment. Also, given the assessment of accommodation as a selfreport measure, this design prevented a direct test of whether the emotional reactivity of the partner to the patient's arousal causes an increased likelihood of accommodation. To explore whether it is this momentary emotional exchange that subsequently leads to increased accommodation, future research could explore other methods to assess accommodation in real time as emotional arousal is assessed. Additionally, to further evaluate the effect that accommodation has on patients' symptom severity, future research with a larger sample could explore how this emotional reactivity within conversations predicts increased partner accommodation, which may then predict worsened symptoms in the patient. The size of the current sample also prevented us from examining how comorbid conditions (such as depression) may influence the present effects. Future research should evaluate how combined psychopathological symptoms influence emotional dynamics within relationships.

Based on these limitations, findings should be considered preliminary and clinical implications should be considered with caution. However, there are possible practical implications for clinicians working with couples with BED. Given the association at pretreatment between high accommodation and emotional coregulation of partners to the patients' emotional arousal, clinicians who work with partners who are highly accommodating may consider assessing the emotional reactivity of partners when interacting with the patients. If partners are accommodating to alleviate their own and/or the patient's negative emotions, treatment geared only toward reduction in accommodating behaviors may fail to address the emotions that evoke these behaviors. Therefore, clinicians could target this specific emotional reactivity in partners to reduce their tendency to engage in unhelpful accommodation.

Whereas patients' overall arousal was lower after treatment, all other effects in the study involved the emotions of the partner. Therefore, this investigation demonstrates the importance of not only investigating the emotions of a patient in isolation but also exploring the emotions of the partner as part of a dynamic interplay of emotions experienced within couples. The specific association between this emotional responding and accommodation calls for further research on the specific emotional antecedents of behaviors that maintain psychopathology. Given that many partners feel compelled to accommodate but often are unaware of the impact of these behaviors, couple-based treatments are fruitful approaches not only to target the emotions and symptoms of the patient but also to target maladaptive behaviors in the partner (Fischer et al., 2017). In conclusion, this pilot investigation points to a potentially important pattern involving the linkages between the interpersonal expression of emotions and behaviors within the context of psychopathology - knowledge which, if replicated, hopefully will translate to the enhancement of treatments to promote not only the emotional health of patients but also that of their committed partners.

\section{REFERENCES}

American Psychiatric Association (2013). Diagnostic and statistical manual of mental disorders (5th ed.). Arlington, VA: American Psychiatric Publishing. 
Atkinson, J. E. (1978). Correlation analysis of the physiological factors controlling fundamental voice frequency. The Journal of the Acoustical Society of America, 63, 211-222. https://doi.org/doi:10.1121/1.381716

Audacity Team. (2018). Audacity(R): Free audio editor and recorder [Computer application]. Version 2.2.2. Retrieved February 20, 2018 from https://audacityteam.org/

Bachorowski, J., \& Owren, M. J. (1995). Vocal expression of emotion: Acoustic properties of speech are associated with emotional intensity and context. Psychological Science, 6, 219-224. https://doi.org/10.1111/j.1467-9280. 1995.tb00596.x

Banse, R., \& Scherer, K. (1996). Acoustic profiles in vocal emotion expression. Journal of Personality and Social Psychology, 70, 614-636. https://doi.org/10.1037/0022-3514.70.3.614

Baucom, B. R. (2010). Power and arousal: New methods for assessing couples. In K. Hahlweg, M. Grawe-Gerber, \& D. H. Baucom (Eds.), Enhancing couples: The shape of couple therapy to come (pp. 171-184). Cambridge, MA: Hogrefe.

Baucom, B. R., Atkins, D. C., Eldridge, K., McFarland, P., Sevier, M., \& Christensen, A. (2011). The language of demand/withdraw: Verbal and vocal expression in dyadic interactions. Journal of Family Psychology, 25, 570580. https://doi.org/10.1037/a002406

Baucom, B. R., Sheng, E., Christensen, A., Georgiou, P. G., Narayanan, S. S., Weusthoff, S., \& Atkins, D. C. (2015). Behaviorally-based couple therapies reduce emotional arousal during couple conflict. Behaviour Research and Therapy, 72, 49-55. https://doi.org/10.1037/fam0000044

Baucom, B. R., Dickenson, J. A., Atkins, D. C., Baucom, D. H., Fischer, M. S., Weusthoff, S. et al. (2015). The interpersonal process model of demand/withdraw behavior. Journal of Family Psychology, 29, 80-90. https://d oi.org/10.1037/fam0000044

Baucom, B. R., Weusthoff, S., Atkins, D. C., \& Hahlweg, K. (2012). Greater emotional arousal predicts poorer long-term memory of communication skills in couples. Behaviour Research and Therapy, 50, $442-447$. https://doi.org/10.1016/j.brat.2012.03.010

Baucom, D. H., Belus, J. M., Adelman, C. B., Fischer, M. S., \& Paprocki, C. (2014). Couple-based interventions for psychopathology: A renewed direction for the field. Family Process, 53, 445-461. https://doi.org/10.1111/famp. 12075

Boeding, S. E., Paprocki, C. M., Baucom, D. H., Abramowitz, J. S., Wheaton, M. G., Fabricant, L. E. et al. (2013). Let me check that for you: Symptom accommodation in romantic partners of adults with obsessive-compulsive disorder. Behaviour Research and Therapy, 51, 316-322. https://doi.org/10.1016/j.brat.2013.03.002

Boersma, P., \& Weenink, D. (2018). Praat: Doing phonetics by computer [Computer program]. Version 6.0.37. Retrieved February 3, 2018, from http://www.praat.org/

Bryan, C. J., Baucom, B. R., Crenshaw, A. O., Imel, Z., Atkins, D. C., Clemans, T. A. et al. (2018). Associations of patient-related emotional bond and vocally encoded emotional arousal among clinicians and acutely suicidal military personnel. Journal of Consulting and Clinical Psychology, 86, 372-383. https://doi.org/10.1037/cc p0000295

Butler, E. A. (2011). Temporal interpersonal emotion systems: The "TIES" that form relationships. Personality and Social Psychology Review, 15(4), 367-393. https://doi.org/10.1177/1088868311411164

Butler, E. A., \& Randall, A. K. (2013). Emotional coregulation in close relationships. Emotion Review, 5, $202-210$. https://doi.org/10.1177/175407391245163

Caporino, N. E., Morgan, J., Beckstead, J., Phares, V., Murphy, T. K., \& Storch, E. A. (2012). A structural equation analysis of family accommodation in pediatric obsessive-compulsive disorder. Journal of Abnormal Child Psychology, 40, 130-143. https://doi.org/10.1007/s10802-011-9549-8

Coan, J. A., \& Maresh, E. L. (2014). Social baseline theory and the social regulation of emotion. In J. J. Gross (Ed.), Handbook of emotion regulation (pp. 221-236). New York: Guilford.

Eisenberg, N., Fabes, R. A., Guthrie, I. K., \& Reiser, M. (2000). Dispositional emotionality and regulation: Their role in predicting quality of social functioning. Journal of Personality and Social Psychology, 78, $136-157$. https://doi.org/10.1037//0022-3514.78.1.136

Eisenberger, N. I., \& Lieberman, M. D. (2004). Why rejection hurts: A common neural alarm system for physical and social pain. TRENDS in Cognitive Sciences, 8, 294-300. https://doi.org/10.1016/j.tics.2004.05.010

First, M. B., Spitzer, R. L., Gibbon, M., \& Williams, J. B. (1996). Structured clinical interview for the DSM-IV Axis I disorders - Patient edition (SCID-I/P, Version 2.0). New York: Biometrics Research Department: New York State Psychiatric Institute.

First, M., Spitzer, R., Gibbon, M., \& Williams, J. (1997). Structured clinical interview for DSM-IV Axis I disorders, research version, Patient edition. New York: Biometrics Research, New York State Psychiatric Institute.

Fischer, M. S., Baucom, D. H., Baucom, B. R., Abramowitz, J. S., Kirby, J. S., \& Bulik, C. M. (2017). Disorder-specific patterns of emotion coregulation in couples: Comparing obsessive compulsive disorder and anorexia nervosa. Journal of Family Psychology, 31, 304-315. https://doi.org/10.1037/fam0000251

Fischer, M. S., Baucom, D. H., Baucom, B. R., Weusthoff, S., Hahlweg, K., Atkins, D. C. et al. (2015). Emotional arousal predicts observed social support in German and American couples taling about breast cancer. Journal of Family Psychology, 29, 744-754. https://doi.org/10.1037/fam0000092 
Fischer, M. S., Baucom, D. H., \& Cohen, M. J. (2016). Cognitive-behavioral couple therapies: Review of the evidence for the treatment of relationship distress, psychopathology, and chronic health conditions. Family Process, 55, 423-442. https://doi.org/10.1111/famp.12227

Fredman, S. J., Vorstenbosch, V., Wagner, A. C., Macdonald, A., \& Monson, C. M. (2014). Partner accommodation in posttraumatic stress disorder: Initial testing of the Significant Others' Responses to Trauma Scale (SORTS). Journal of Anxiety Disorders, 28, 372-381. https://doi.org/10.1016/j.janxdis.2014.04.001

Gormally, J., Black, S., Daston, S., \& Rardin, D. (1982). The assessment of binge eating severity among obese persons. Addictive Behaviors, 7, 47-55. https://doi.org/10.1016/0306-4603(82)90024-7

Heatherton, T. F., \& Baumeister, R. F. (1991). Binge eating as escape from self-awareness. Psychological Bulletin, 110, 89-108. https://doi.org/10.1037/0033-2909.110.1.86

IBM Corp. (2016). IBM SPSS statistics for Windows, Version 24.0. Armonk, NY: IBM Corp.

John, O. P., \& Gross, J. J. (2004). Healthy and unhealthy emotion regulation: Personality processes, individual differences, and life span development. Journal of Personality, 72, 1301-1333. https://doi.org/10.1111/j.14676494.2004.00298.x

Juslin, P. N., \& Scherer, K. R. (2005). Vocal expression of affect. In K. R. Scherer \& R. Rosenthal (Eds.), The new handbook of methods in nonverbal behavior research (pp. 65-135). New York, NY: Oxford University Press.

Kenny, D. A., Kashy, D. A., \& Cook, S. M. (2006). Dyadic data analysis. New York, NY: Guilford.

Kenward, M. G., \& Roger, J. H. (2009). An improved approximation to the precision of fixed effects from restricted maximum likelihood. Computational Statistics \& Data Analysis, 53, 2583-2595. https://doi.org/10.1016/j.csda. 2008.12 .013

Kirby, J. S., Runfola, C. D., Baucom, D. H., \& Bulik, C. M. (2014). UNiting couples In the Treatment of Eating disorders (UNITE). Unpublished treatment manual.

Kirby, J. S., Runfola, C. D., Fischer, M. S., Baucom, D. H., \& Bulik, C. (2017). Couple-based interventions for adults with eating disorders. In S. B. Murray, L. K. Anderson, L. Cohn, S. B. Murray, L. K. Anderson \& L. Cohn (Eds.), Innovations in family therapy for eating disorders: Novel treatment developments, patient insights, and the role of carers (pp. 135-143). New York, NY, US: Routledge/Taylor \& Francis Group.

Kleinbaum, D. G., \& Kupper, L. L. (1978). Applied regression analysis and other multivariable methods. Boston, MA: Duxbury.

Leehr, E. J., Krohmer, K., Schag, K., Dresler, T., Zipfel, S., \& Giel, K. E. (2015). Emotion regulation model in binge eating disorder and obesity- a systematic review. Neuroscience and Biobehavioral Reviews, 49, 125-134. https://doi.org/10.1016/j.neubiorev.2014.12.008

Maas, C. J., \& Hox, J. J. (2005). Sufficient sample sizes for multilevel modeling. Methodology, 1, 86-92. https://d oi.org/10.1027/1614-1881.1.3.86

McNeish, D. M., \& Stapleton, L. M. (2016). Modeling clustered data with very few clusters. Multivariate Behavioral Research, 51, 495-518. https://doi.org/10.1080/00273171.2016.1167008

Owren, M. J., \& Bachorowski, J.-A. (2007). Measuring emotion-related vocal acoustics. In J. J. B. Allen \& J. A. Coan (Eds.), Handbook of emotion elicitation and assessment (pp. 239-266). Oxford, UK: Oxford University Press.

Perry, N. S., Baucom, K. J. W., Bourne, S., Butner, J., Crenshaw, A. O., Hogan, J. N. et al. (2017). Graphic methods for interpreting longitudinal dyadic patterns from repeated-measures actor-partner interdependence models. Journal of Family Psychology, 31, 592-603. https://doi.org/10.1037/fam0000293

R Studio Team (2015). RStudio: Integrated development for R. Boston, MA: RStudio, Inc. Retrieved from http:// www.rstudio.com/

Randall, A. K., Post, J. H., Reed, R. G., \& Butler, E. A. (2013). Cooperating with your romantic partner: Associations with interpersonal emotion coordination. Journal of Social and Personal Relationships, 30, 1072-1095. https://doi.org/10.1177/0265407513481864

Reuman, L., \& Abramowitz, J. S. (2017). Predictors of accommodation among families affected by fear-based disorders. Child Psychiatry and Human Development, 49, 53-62. https://doi.org/10.1007/s10578-017-0728-x

Runfola, C. D., Kirby, J. S., Baucom, D. H., Fischer, M. S., Baucom, B. R., Matherne, C. E. et al. (in press). A pilot open trial of UNITE-BED: A couple-based intervention for binge-eating disorder. International Journal of Eating Disorders.

Rusbult, C. E., Verette, J., Whitney, G. A., Slovik, L. F., \& Lipkus, I. (1991). Accommodation processes in close relationships: Theory and preliminary empirical evidence. Interpersonal Relations and Group Processes, 60, 53-78. https://doi.org/10.1037/0022-3514.60.1.53

Salerno, L., Rhind, C., Hibbs, R., Micali, N., Schmidt, U., Gowers, S. et al. (2016). An examination of the impact of care giving styles (accommodation and skillful communication and support) on the one year outcome of adolescent anorexia nervosa: Testing the assumptions of the cognitive interpersonal model in anorexia nervosa. Journal of Affective Disorders, 191, 230-236. https://doi.org/10.1016/j.jad.2015.11.016

Salkovskis, P. M. (1996). The cognitive approach to anxiety: Threat beliefs, safety seeking behaviour, and the special case of health anxiety and obsessions. In P. M. Salkovskis (Ed.), Frontiers of cognitive therapy (pp. 48-74). New York: Guilford. 
SAS Institute Inc. (2013). SAS/GRAPH 9.4: Reference. Cary, NC: SAS Institute Inc.

Sbarra, D. A., \& Hazan, C. (2008). Coregulation, dysregulation, self-regulation: An integrative analysis and empirical agenda for understanding adult attachment, separation, loss, and recovery. Personality and Social Psychology Review, 12, 141-167. https://doi.org/10.1177/1088868308315702

Scherer, K. R. (1986). Vocal affect expression: A review and a model for future research. Psychological Bulletin, 99, 143-165. https://doi.org/10.1037/0033-2909.99.2.143

Sepulveda, A. R., Kyriacou, O., \& Treasure, J. (2009). Development and validation of the Accommodation and Enabling Scale for Eating Disorders (AESED) for caregivers in eating disorders. BMC Health Services Research, 9, 171-184. https://doi.org/10.1186/1472-6963-9-171

Timmerman, G. M. (1999). Binge Eating Scale: Further assessment of validity and reliability. Journal of Applied Biobehavioral Research, 4, 1-12. https://doi.org/10.1111/j.17519861.1999.tb00051.x

Timmons, A. C., Margolin, G., \& Saxbe, D. E. (2015). Physiological linkage in couples and its implications for individual and interpersonal functioning: A literature review. Journal of Family Psychology, 29, 720-731. https://doi.org/10.1037/fam0000115

Treasure, J., \& Todd, G. (2016). Interpersonal maintaining factors in eating disorder: Skill sharing interventions for carers. In Y. Latzer \& D. Stein (Eds.), Bio-psycho-social contributions to understanding eating disorders (pp. 125-137). Cham, Switzerland: Springer International Publishing.

U.S. Census Bureau (2016). MS-1. Marital status of the population 15 years old and over by sex, Race and Hispanic origin: 1950 to present. Retrieved from https:/www.census.gov/data/tables/time-series/demo/families/ marital.html.

Werner, K., \& Gross, J. J. (2010). Emotion regulation and psychopathology: A conceptual framework. In A. M. Kring \& D. M. Sloan (Eds.), Emotion regulation and psychopathology: A transdiagnostic approach to etiology and treatment (pp. 13-37). New York: Guilford.

Weusthoff, S., Baucom, B. R., \& Hahlweg, K. (2013). Fundamental frequency during couple conflict: An analysis of physiological, behavioral, and sex-linked information encoded in vocal expression. Journal of Family Psychology, 22(2), 212-220. https://doi.org/10.1037/a0031887 